\title{
Development of Communication Competence in Pre-Service Vocational Education Teacher Training
}

\author{
Daniel Etzold ${ }^{1} \&$ Marc Krüger ${ }^{2}$ \\ ${ }^{1}$ Karl-Heine-Schule - Berufliches Schulzentrum der Stadt Leipzig, Leipzig, Germany \\ ${ }^{2}$ Münster School of Vocational Education, FH Münster - University of Applied Science, Münster, Germany \\ Correspondence: Daniel Etzold, Karl-Heine-Schule Berufliches Schulzentrum der Stadt Leipzig, Germany. \\ E-mail: d.etzold@bszkhs-leipzig.lernsax.de
}

Received: April 19, $2021 \quad$ Accepted: August 27, $2021 \quad$ Online Published: September 23, 2021
doi:10.5539/hes.v11n4p31

\begin{abstract}
This paper presents a seminar concept for the development of communication competence in pre-service vocational education teachers with the aid of video annotations, feedback, and peer microteaching. The seminar is offered within a teacher training program for students taking a master's degree (MEd) in vocational education at the FH Münster University of Applied Sciences, Germany, and has been conducted three times. The advantages of the seminar concept are manifold. On the one hand, we create a learning environment in which students individually prepare and conduct five peer microteaching lessons in a row and receive prompt and constructive peer feedback on every performance. On the other hand, the quality of feedback improves so that our students are professional feedback providers by the end of the seminar. The provision of teacher feedback alone does not help our students become successful feedback providers. Nor, given the resources available at the university, is it a realistic alternative in terms of time constraints. In addition, due to recordings, the students gain a better insight into their teaching skills since their lessons can be observed and approached from an outside perspective.
\end{abstract}

Keywords: digital peer feedback, microteaching, pre-service vocational education, teacher training program

\section{Introduction}

Communication is one of the most essential premises of teaching and learning in the classroom (Simpllico, 2007; White, 2016). Hence, there can be no doubt that teachers need to develop communication competence throughout their academic careers to become successful at interpreting and creating communicative situations. Despite this, scholars have reported that new teachers often do not possess the repertoire of teaching strategies and skills they need for their daily practice (Freiberg, 2002; Liston, Whitcomb, \& Borko, 2006). Student teachers face difficulties in generalizing their skills and transferring them to the classroom (Markelz, Riden, \& Scheeler, 2017; Scheeler, 2008). As a result, there is an urgent requirement for courses that help them overcome these deficits.

White (2016) provides a useful model for the development of communication competence. According to the model, communication competence comprises knowledge, judgment, practice, and evaluation. The model allows students to reflect upon their communication and discuss the choices they make rather than defining clear-cut rules that would not apply to every communicative situation anyway. It seeks primarily to train teachers to become more competent communicators by “... developing, choosing, practicing and evaluating a repertoire of communication skills" (p. 41). An understanding of the development of communication competence as a process involving all these aspects underpins our seminar concept, which was designed specifically for preservice vocational education teachers at the FH Münster University of Applied Sciences, Germany. It was conceptualized and introduced in 2016 and fine-tuned in response to course evaluations. We aim through the present study to share our concept, which involves peer microteaching and video feedback in the form of annotations. Several studies have shown the usefulness of these approaches (e.g., Anderson, Kennedy-Clark, \& Galstaun, 2012; Colasante \& Leedham, 2013; Ellis, McFadden, Anwar, \& Roehrig, 2015; McFadden, Ellis, Anwar, \& Roehrig, 2014; Picci, Calvani, \& Bonaiuti, 2012; Van der Westhuizen, 2015).

Our article is organized as follows: The first section offers an overview of the seminar's theoretical 
underpinnings and places peer microteaching and video feedback in historical context. The next section explains the concept in detail. Finally, its benefits are outlined and suggestions are made for future research directions.

\section{Theoretical Background}

Communication competence is essential for prospective teachers. Studies in classroom interaction emerged in the 1930s and increased substantially in number in the 1960s when novel approaches to learning and teaching were needed in response to societal changes and the greater diversity of the student population (Skukauskaite, Rangel, Rodriguez, \& Ramón, 2015). A plethora of teacher training concepts combining scientific knowledge and education practice emerged henceforth.

Microteaching, a now widely applied training methodology, was introduced in 1959 and began to receive much scholarly attention thereafter (Allen, 1980). It was developed by scholars at Stanford University and had three main purposes: "[...] (1) as preliminary experience and practice in teaching, (2) as a research vehicle to explore training effects under controlled conditions, and (3) as an in-service training instrument for experienced teachers" (Fortune, Cooper, \& Allen, 1967, p. 389). Early sessions, which were sometimes recorded, involved a teacher delivering lessons to one to five students for five to 20 minutes (Allen, 1966). Microteaching and related methods began to be applied in countries such as Australia, the United Kingdom, and Germany (Klinzing \& Aliosio, 2006).

In 1960s Europe, teacher training was renegotiated in different academic disciplines (Klinzing \& Floden, 1991). Zifreund (1966), a German scholar at the University of Tübingen, used role-playing students as the audience during microteaching sessions and video recordings as mandatory elements of the teacher training program. Zifreund was one of the first to make use of what we now call peer teaching a special type of microteaching (Klinzing, 2002). It was characterized by audiences comprising the teacher's peers such as other students or experienced teachers.

The purported advantages of microteaching have sometimes been called into question, but an analysis of more than 200 studies revealed the effectiveness of the approach at least in teacher training (Klinzing, 2002). Most of the research results supported the assumption that microteaching in both pre- and in-service education led to positive and long-term benefits in terms of the acquisition of verbal and non-verbal behavioral patterns, the integration of what had been learned during training into the individual behavioral repertoire, and professional practice. The value of microteaching in teacher education should therefore not be underestimated. Its use in teacher education courses is beyond doubt worthy of reconsideration given curriculum demands for the development of communication competence.

Technologies such as video annotation tools have been shown to be immensely helpful in teaching and learning. Studies focusing on the use of video annotation tools in teacher training have increased in number since 2010 (Pérez-Torregrosa, Díaz-Martín, \& Ibáñez-Cubillas, 2017). Research has been carried out on the juxtaposition of existing video annotation tools (Rich \& Hannafin, 2009), guiding questions for their appropriate use (Rich \& Trip, 2011), and the promotion of reflective practice among student teachers (Alley \& King, 2015; Ellis et al., 2015; McFadden et al., 2014; Van der Westhuizen, 2015). In a study by Anderson, Kennedy-Clark, and Galstaun (2012), pre-service teachers considered microteaching and feedback via video annotations to be very helpful. Anderson et al.'s (2012) findings revealed that students recognized the usefulness of enhanced video annotation (EVA) tools. They could observe themselves before they became professional teachers and reflect upon and revisit their peers' feedback.

Van der Westhuizen (2015) also reported that students valued EVA in microteaching sessions. They "were able to reflect more thoroughly on their own micro-lessons, which helped them to improve their lessons more than other methods do" (p. 102). Van der Westhuizen stressed the "greatly increased reflection, feedback and assessment opportunities" that video annotations offered (p. 105).

In sum, the research suggests that microteaching and video feedback in the form of annotations are highly effective, especially for reflective practice. Accordingly, conceptualizing and conducting seminars that aim to develop students' teaching skills by incorporating these approaches are highly desirable at university level.

\section{Putting Theory into Practice: A Seminar for Preservice Vocational Education Teachers}

The seminar we devised is offered to preservice vocational education teachers at the FH Münster. It is part of an advanced teacher training module in specialized didactics and can be taken by students studying for a master's degree (MEd) in vocational education. However, participation in our seminar is not obligatory for student teachers. While there are no criteria for selection, the number of students enrolled must not exceed 18 . This guarantees an optimum learning environment. The seminar has been offered three times as of the summer term 
of 2017. It has been optimized continually based on course evaluations, so the refined concept can now be presented and discussed.

\subsection{Primary Objectives of the Seminar}

The main goal of our seminar is to expand prospective teachers' repertoire of communication skills and enable them to become effective communicators in the classroom. Since communication in a classroom environment is a rather complex phenomenon and prone to misunderstanding (Santandreu, Shurden \& Shurden, 2011; Simpllico, 2002; Zhanabekova, 2014), we aim to uncover students' strengths and development potential rather than simply measure and judge their overall communication competence. Hence, we seek to point out the positive as well as negative effects of our students' communication behavior to provide a solid basis for their development in the practical training phases of the course. We also give them room to reflect on and discuss their progress.

The secondary objective of our seminar concerns our student teachers' prospective learners, who also need to develop communication competence, a prerequisite for every profession. In particular, we explain how to give constructive feedback on learners' communication competence and raise our students' awareness of the importance of communication in professional settings. In addition, we attempt to overcome prospective teachers' reluctance to use technologies such as EVA in their classroom, as reported in the literature (e.g., Anderson et al., 2012; Kennedy-Clark, 2011). We do this by pointing out that these tools facilitate constructive feedback in a way that traditional methods such as questionnaires or oral feedback do not.

\subsection{Developing Communication Competence}

To enable our student teachers to improve their classroom communication, regardless of the skills they already possess, we use White's (2016) elaboration on teacher communication competence as a starting point. Figure 1 shows the four components of communication competence: knowledge, judgment, practice, and evaluation.

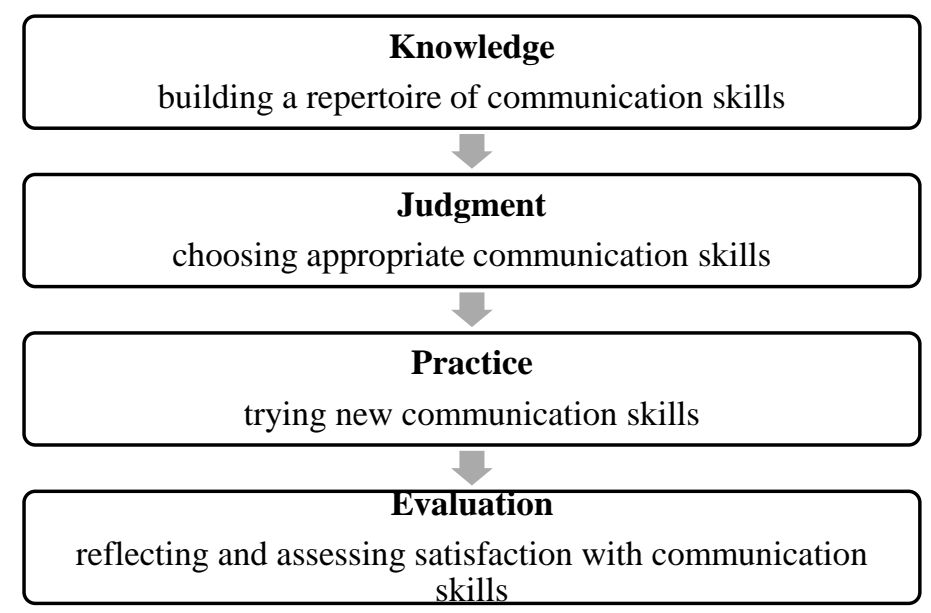

Figure 1. Components of communication competence. Adapted from White (2016, p. 43)

Whereas White (2016) lists the characteristics of communication competence and defines them as cited above, we added an underlying process and applied this process in practice. This is to say that we created an approach consisting of eight steps teacher students' go through in every peer microteaching session they prepare, conduct, record, and evaluate. In detail, these steps are organized as follows: (1) dealing with theory and scientific findings, (2) discussing feedback criteria, (3) applying feedback criteria to sample videos, (4) preparing peer microteaching, (5) performing and recording peer microteaching, (6) providing video feedback, (7), reviewing video feedback comments, and (8) reflecting upon one's performance. By contrasting these steps with White's (2016) model, an allocation becomes apparent as depicted in table 1. 
Table 1. Implementation of White's (2016, p. 43) components of communication competence

\begin{tabular}{ll}
\hline $\begin{array}{l}\text { Steps students go through in five } \\
\text { communicative situations }\end{array}$ & $\begin{array}{l}\text { Component of communication competence } \\
\text { according to White }(2016, \mathrm{p} .43)\end{array}$ \\
\hline 1 Dealing with theory and scientific findings & Knowledge \\
2 Discussing feedback criteria & Knowledge \\
3 Applying feedback criteria to sample videos & Knowledge \\
4 Preparing peer microteaching & Judgment \\
5 Performing and recording peer Microteaching & Practice \\
6 Providing video feedback & Evaluation \\
7 Reviewing video feedback comments & Evaluation \\
8 Reflecting upon one's performance & Evaluation \\
\hline
\end{tabular}

Note. White's (2016, p. 43) categories functioned as a starting point to develop eight steps students go through in each of the five communicative situations discussed in class.

Table 1 shows the abovementioned eight steps students undergo for each microteaching situation and corresponding components of communication competence as suggested by White (2016). Within the course of our seminar, students go through the entire process portrayed above five times. In the following, a closer look at the steps mentioned in the table above is given. The group allocation is addressed beforehand to better understand the procedure that follows.

\subsection{Group Allocation}

At beginning of our seminar, students are divided into groups of three, and they remain in these for the duration of the course. The groups comprise students from different fields of study, for instance nutrition and home economics, constructional engineering, and electrical engineering. This creates a heterogeneity that reflects a real classroom. Within the course of the seminar, two of the groups work together when peer microteaching lessons are being conducted. However, videos are only made available to the initial groups for privacy reasons. We use the EVA tool edubreak®.

\subsection{Dealing with Theoretical and Scientific Findings on Classroom Communication}

The main theoretical issues can be summarized under two headings, namely cross-situational communication and situation-specific communication. In the case of the former, we initially address commonly established communication models such as Schulz von Thun (1981), Watzlawick, Beavin-Bavelas, and Jackson (1967), and Weaver and Shannon (1949) to approach teachers' verbal, non-verbal, and para-verbal communication behavior. The first communicative situation we deal with in detail is an introduction to an allocated class from the students' occupational fields. For example, students from the field of nutrition and home economics introduce themselves to a fictive, first-year vocational school class of prospective food technologists. With the aid of the aforementioned communication models, students approach various aspects of their verbal, non-verbal, and para-verbal communication behaviors to obtain an introductory overview of their strengths and weaknesses. The situation-specific communication aspects, which are addressed in class afterward, comprise the following topics: teacher talks, classroom conversations, thought-provoking questions, and technical discussions. Theories of communication skills and criteria, tailored to the individual disciplines, are used as a starting point.

After the introduction, students are taken through five communicative situations that frequently occur in vocational college classrooms. We tend to begin with fundamental communication aspects such as verbal, non-verbal, and para-verbal communication behaviors and end with the specific forms of communication that are prevalent in vocational training. We prefer to take this approach rather than focus on the general aspects of communication.

\subsection{Discussing Feedback Criteria}

After a theoretical investigation of the topics, the students discuss corresponding feedback criteria. They take an overview of the several aspects that can be considered when giving professional feedback with regard to the particular situation. Feedback criteria are always deduced from the previous theoretical discussions. This helps our students internalize the knowledge they have acquired.

\subsection{Applying Feedback Criteria to Sample Videos}

Feedback criteria for every communicative situation are also applied to sample videos provided by the seminar teachers. These videos show the specific communicative situations we address in class such as introductions to 
given courses, teacher talks, classroom conversations, thought-provoking questions, and technical discussions. Since it has worked out very well so far, we use two forms of videos to give exemplary feedback: videos of peer-microteaching lessons taught in other seminar groups from the previous year and videos recorded in an authentic vocational college classroom.

The purpose of using these videos and giving exemplary feedback is twofold. First, the students can immediately apply the feedback criteria they have discussed on a theoretical basis. This boosts learning efficiency. Second, they learn how to provide feedback that is sufficiently constructive to achieve a maximum learning opportunity for the recipient. At this stage, video feedback is first provided orally in class. Then, the students' comments are written down in the form of video annotations.

\subsection{Preparing for Peer Microteaching}

After a practical examination of sample videos in class, students individually prepare a peer microteaching session with a focus on the theoretical issue raised in the preceding seminar. Everyone prepares their own microteaching lesson of five to 10 minutes. The lessons pertain to the students' vocational fields. Considerations concerning teacher communication within the scope of our students' preparation must be written down and handed in at the end.

\subsection{Conducting and Recording a Peer Microteaching Session}

The microteaching is performed in groups of six. They are taught by one student and must not exceed a time frame of 10 minutes. Again, the groups do not change during the seminar, so the students can familiarize themselves with their immediate peers. This way, we provide an environment akin to real courses in school. Every lesson is recorded with the aid of a small action camera. The results are immediately uploaded on edubreak ${ }^{\circledR}$ so that students can annotate their peers' videos over the next week.

\subsection{Providing Video Feedback}

Providing video feedback in the form of video annotations is fundamental to our seminar concept. Feedback must be constructive so that the recipient can use it to develop. We regard the following to be indispensable elements of a feedback comment:

- A clear and neutral description of the phenomenon observed

- A description of the corresponding effect on the feedback provider

- A reference to the literature (if applicable)

- A precise suggestion for improvement

- A link to other videos of the feedback receiver or a link to another sequence within the same video (if applicable)

As seminar teachers, we check whether these components are part of every feedback comment. This guarantees that nobody receives insufficient feedback. An exemplary comment is shown in Figure 2.

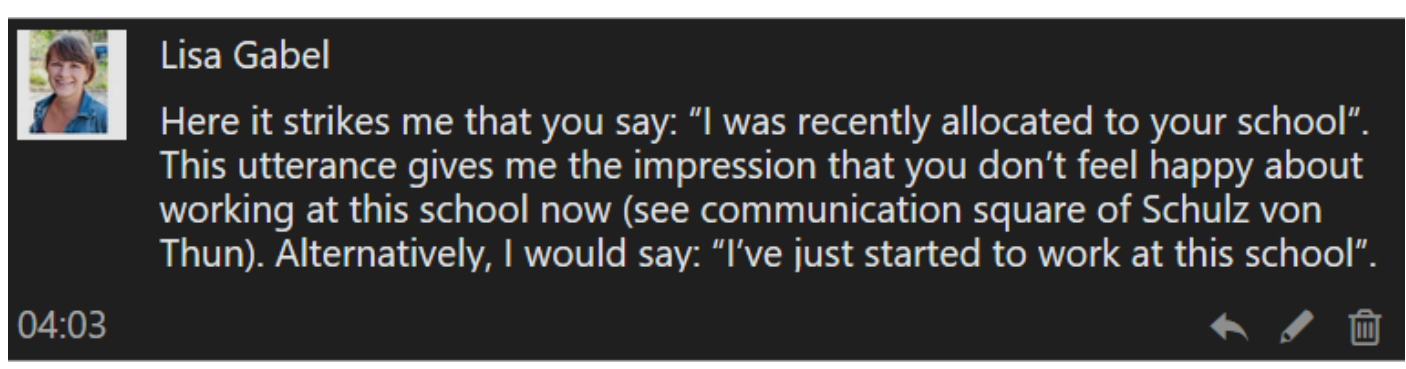

Figure 2. Exemplary feedback comment

Group members are assigned individual roles as part of the feedback process. The videotaped student watches their performance and considers and reflects upon the feedback comments, as well as their own impression of what they have seen and heard. One group member is assigned to give feedback on cross-situational feedback criteria, that is to say, they focus on verbal, non-verbal, and para-verbal communication behaviors with the aid of the general communication models we have discussed at the beginning of the seminar. This person observes the videotaped student with reference to the five communicative situations and provides feedback on their development. The second group member refers to the situation-specific feedback criteria. They also give 
feedback, again with reference to the five communicative situations. As the situation-specific feedback criteria change from video to video, attention must be drawn to the individual characteristics of the particular situation rather than general communication behavior. For instance, regarding thought-provoking questions, the group member looks at how questions are formulated and what answers are elicited from the pupils as a result. The second group member also functions as a watchdog, which means that they are also responsible for the quality of the feedback comments. We know from experience that this role needs to be clearly assigned to ensure high feedback quality across all comments. Figure 3 provides an overview of feedback roles and how these are assigned within each group.

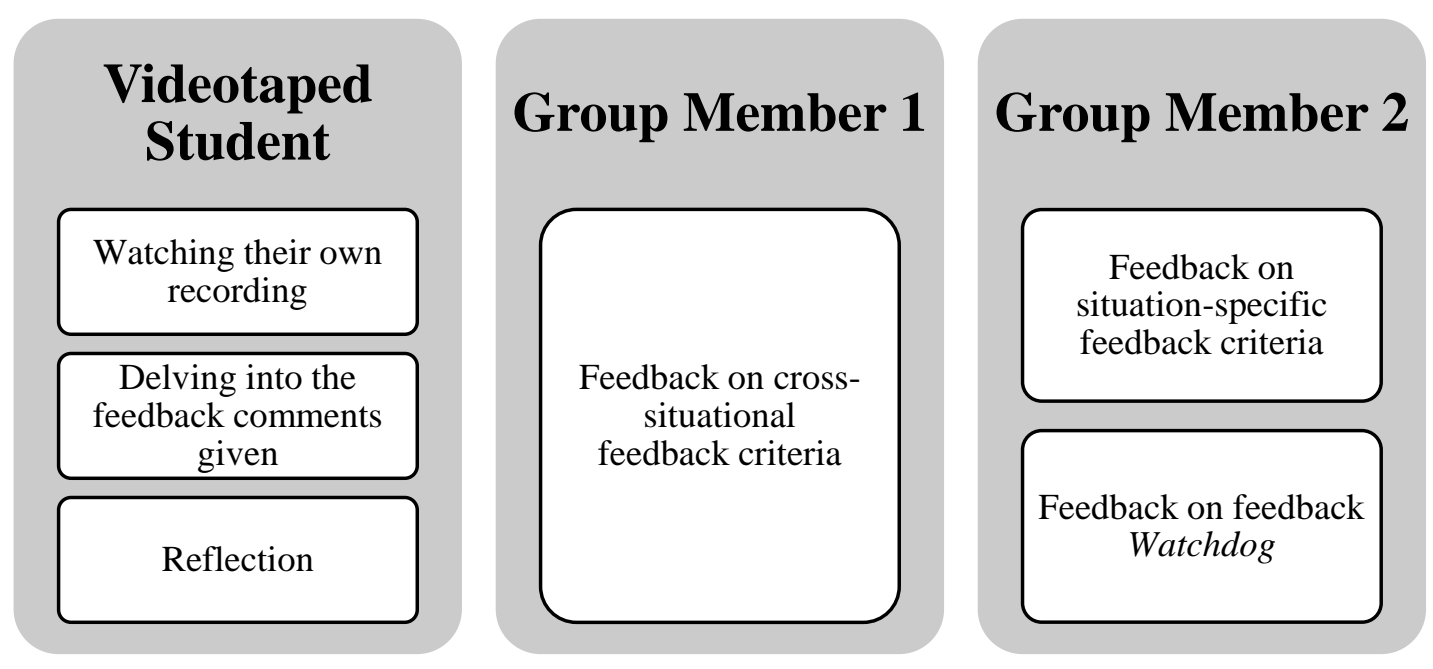

Figure 3. Feedback roles and assigned tasks

During the feedback process, we use edubreak ${ }^{\circledR}$ as our supporting video annotation tool. This can be accessed online and allows for exchanges and cooperative work on video recordings independent of time and location. Video comments can be specified with the aid of a traffic light system and symbols. It also enables our students to respond quickly to video feedback if necessary. Figure 4 shows how edubreak® is used in our seminars.

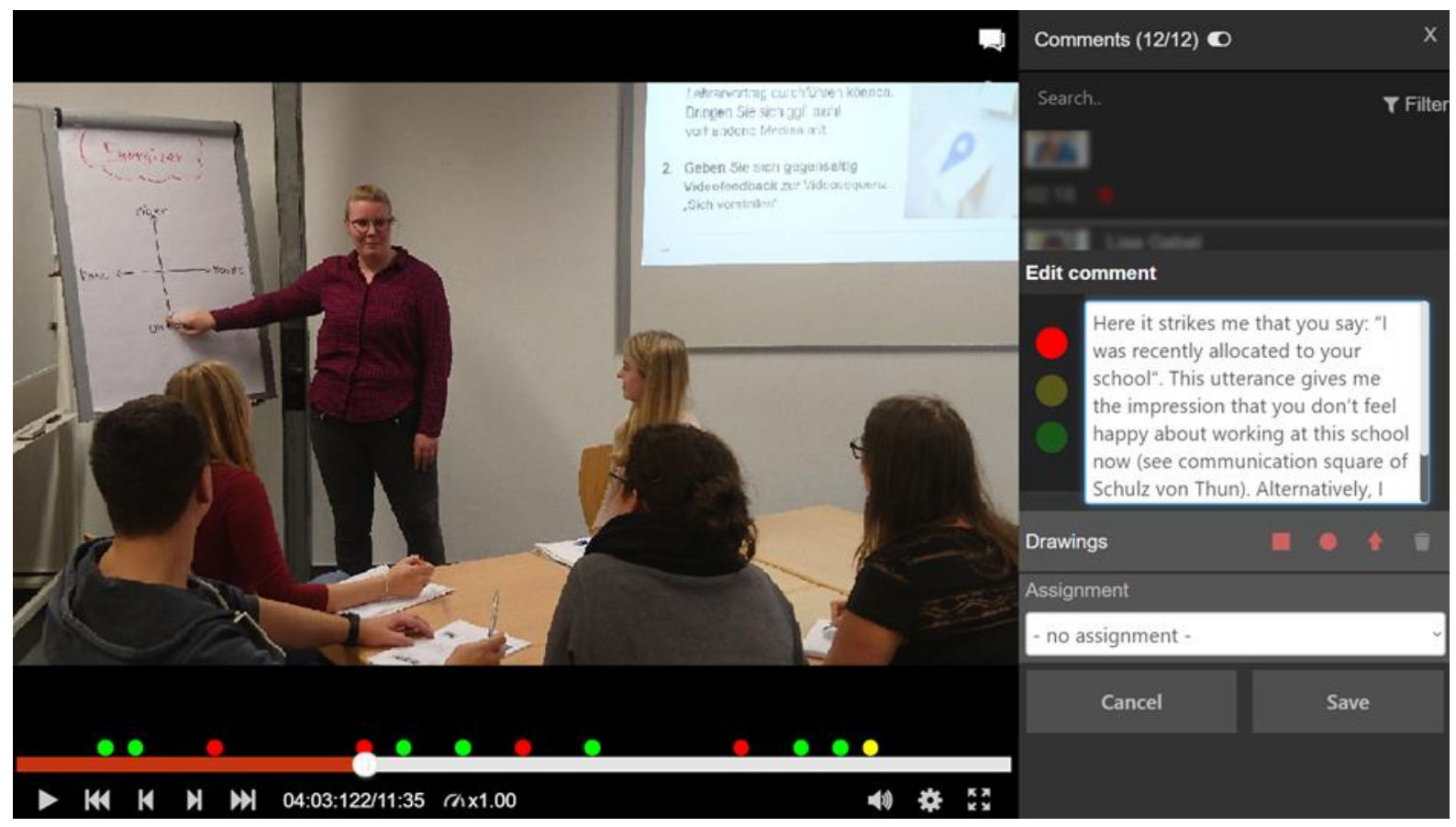

Figure 4. Video annotation with edubreak ${ }^{\circledR}$ 


\subsection{Reviewing Video Feedback Comments}

The penultimate task for the student who has prepared and conducted the peer microteaching lesson is to read the feedback comments. Students need to review these critically. Here, the focus is on the recipient; it is they who decide what conclusions need to be drawn.

\subsection{Reflecting upon One's Performance}

The aim of the last step is to give the student the space to re-think their own performance in light of the video annotations. They do this with the help of guiding reflective questions. Again, it is the recipient of the feedback who draws the conclusions. They then point out what they might do to become more professional. In the closing session of our seminar, each student is given the chance to reflect critically upon their performance. With the help of the students, we seek to show how acquired teaching skills can eventually be transferred to the real classroom and how weaknesses can be eliminated step by step.

\section{Conclusion}

Addressing communication skills within teacher training courses at university, practicing them, and receiving immediate feedback on one's performance through video annotations can be seen as essential steps in preparing students for the communicative situations they will face in the classroom. Peer microteaching and video feedback through video annotations are effective ways to develop communication skills. White's (2016) model provides a valuable starting point for conceptualizing and implementing our seminar because it can be used to help students acquire those skills gradually.

The advantages of our seminar concept are manifold. First, we can use it to create a learning environment in which students individually prepare and conduct peer microteaching lessons five times in a row and receive prompt and constructive feedback on every performance. Unlike conventional teacher training seminars, our seminar gives our students the opportunity (through extensive peer microteaching and video feedback) to focus on their strengths and weaknesses. Second, our students become highly professional feedback providers. Unlike traditional courses, all students must offer their peers regular and constructive feedback. There is no doubt that providing and receiving feedback helps our students to develop and to take criticism. Teacher feedback alone cannot help our students become successful feedback providers. Given the resources that are available to us, it cannot be as comprehensive as student feedback. Third, by recording their performances, students gain a better insight into their teaching skills since their lessons can be assessed from a more objective perspective. They can compare their own impression of their teaching skills with the video feedback comments provided by their peers. Finally, our approach not only facilitates the development of the students' communication competence but also their ability to cultivate it in their learners.

A problem we face is that traditional models do not apply to our video feedback concept because the latter recognizes communication as a complex phenomenon and focuses on the students' strengths and weaknesses rather than judging their communication competence as a whole. Research into resolving this conundrum is in progress. Another issue that might be addressed in the future is the degree to which our students apply their newly acquired skills and use these to eliminate their weaknesses. It would also be interesting to examine the extent to which our students become more sensitized to the importance of communication competence after they have participated in our seminar and how far their positions on the subject change over time. Long-term studies would be needed here. Nevertheless, we would suggest that our approach is an effective way of developing communication competence in pre-service vocational education teacher training.

\section{References}

Allen, D. W. (1966). Micro-teaching: A new framework for in-service education. The High School Journal, 49(8), 355-362. Retrieved from http://www.jstor.org/stable/40366236

Allen, D. W. (1980). Microteaching: A personal review. British Journal of Teacher Education, 6(2), 147-151. https://doi.org/10.1080/0260747800060206

Alley K., \& King, J. (2015). Capturing Quality Practice: Annotated Video-Based Portfolios and Graduate Students' Reflective Thinking. In E. Ortlieb, M. B. Mcvee \& L. E. Shanahan (Eds.), Video Reflection in Literacy Teacher Education and Development: Lessons from Research and Practice (Literacy Research, Practice and Evaluation, Volume 5) (pp. 279- 295). Bingley: Emerald Group Publishing Limited. https://doi.org/10.1108/S2048-045820150000005020

Anderson, K., Kennedy-Clark, S., \& Galstaun, V. (2012). Using Video Feedback and Annotations to Develop ICT Competency in Pre-Service Teacher Education. Joint Australian Association for Research in Education 
and Asia-Pacific Educational Research Association Conference. Retrieved from https://files.eric.ed.gov/fulltext/ED544519.pdf

Colasante, M. \& Leedham, M. (2013). Motivation and satisfaction for vocational education students using a video annotation tool. In H. Carter, M. Gosper \& J. Hedberg (Eds.), ASCILITE 2013 - Annual conference of the Australian Society for Computers in Tertiary Education. Electric Dreams, Sydney, Australia. Retrieved from http://researchbank.rmit.edu.au/view/rmit:23003/n2006043457.pdf

Ellis, J., McFadden, J., Anwar, T., \& Roehrig, G. (2015). Investigating the social interactions of beginning teachers using a video annotation tool. Contemporary Issues in Technology and Teacher Education, 15(3), 404-421. Retrieved from

http://www.citejournal.org/volume-15/issue-3-15/general/investigating-the-social-interactions-of-beginningteachers-using-a-video-annotation-tool

Fortune, J. C., Cooper, J. M., \& Allen, D. W. (1967). The Stanford summer micro-teaching clinic, 1965. Journal of Teacher Education, 18(4), 389-393. https://doi.org/10.1177/002248716701800402

Freiberg, H. J. (2002). Essential Skills for New Teachers. Educational Leadership, 59(6), 56-60. Kennedy-Clark, S. (2011). Pre-service teachers' perspectives on using scenario-based virtual worlds in science education. Computers \& Education, 57(4), 2224-2235. https://doi.org/10.1016/j.compedu.2011.05.015

Klinzing, H. G. (2002). Wie effektiv ist Microteaching? Ein Überblick über fünfunddreißig Jahre Forschung. Zeitschrift für Pädagogik, 48(2), 194-214. Retrieved from

https://www.pedocs.de/volltexte/2011/3829/pdf/ZfPaed_2_2002_Klinzing_Wie_effektiv_ist_Microteaching _D_A.pdf

Klinzing, H. G., \& Aloisio, B. G. (2006). Does the Improvement of Nonverbal Skill Flow on to Changes in Personality Dimensions? Six Experimental Investigations on the Effects of Nonverbal-Behavior Training in Laboratory Settings on "Charisma", Directiveness, Extraversion, Locus-of-Control Orientation, and Self Efficacy. Association of Teacher Education in Europe - 31st annual atee Association of Teacher Education in Europe conference. Retrieved from http://citeseerx.ist.psu.edu/viewdoc/download?doi=10.1.1.554.2013\&rep=rep1\&type=pdf

Klinzing, H. G., \& Floden, R. E. (1991). The Development of the Microteaching Movement in Europe. Paper presented at the Annual Meeting of the American Educational Research Association in Chicago, IL. Retrieved from https://files.eric.ed.gov/fulltext/ED352341.pdf

Liston, D., Whitcomb, J., \& Borko, H. (2006). Too Little or Too Much: Teacher Preparation and the First Years of Teaching. Journal of Teacher Education, 57(4), 351-358. https://doi.org/10.1177/0022487106291976

Markelz, A., Riden, B., \& Scheeler, M. C. (2017). Generalization Training in Special Education Teacher Preparation: Does It Exist?. Teacher Education and Special Education, 40(3), 179-193. https://doi.org/10.1177/0888406417703752

McFadden, J., Ellis, J., Anwar, T., \& Roehrig, G. (2014). Beginning Science Teachers' Use of a Digital Video Annotation Tool to Promote Reflective Practices. Journal of Science Education and Technology, 23(3), 458-470. https://doi.org/10.1007/s10956-013-9476-2

Pérez-Torregrosa, A. B., Díaz-Martín, C., \& Ibáñez-Cubillas, P. (2017). The use of Video annotation tools in teacher training. Procedia-Social and Behavioral Sciences, 237, 458-464.

https://doi.org/10.1016/j.sbspro.2017.02.090

Picci, P., Calvani, A., \& Bonaiuti, G. (2012). The Use of Digital Video Annotation in Teacher Training: The Teachers' Perspectives. Procedia-Social and Behavioral Sciences, 69, 600-613. https://doi.org/10.1016/j.sbspro.2012.11.452

Rich, P. J., \& Hannafin, M. (2009). Video annotation tools: Technologies to scaffold, structure, and transform teacher reflection. Journal of Teacher Education, 60(1), 52-67. https://doi.org/10.1177/0022487108328486

Santandreu, R. J., Shurden, S., \& Shurden, M. (2011). The Complexity of Communication in a Course Environment: A Case Study. Journal of Case Studies in Education, 2. Retrieved from https://files.eric.ed.gov/fulltext/EJ1057194.pdf

Scheeler, M. C. (2008). Generalizing Effective Teaching Skills: The Missing Link in Teacher Preparation. Journal of Behavioral Education, 17(2), 145-159. https://doi.org/10.1007/s10864-007-9051-0

Schulz von Thun, F. (1981). Miteinander reden. Störungen und Klärungen. Allgemeine Psychologie der 
Kommunikation. Reinbek: Rowohlt.

Shannon, C. E., \& Weaver, W. (1949). The Mathematical Theory of Communication. Urbana, IL: University of Illinois Press.

Simpllico, J. S. C. (2007). Educating the 21st Century Student. Bloomington, IN: AuthorHouse.

Skukauskaite, A., Rangel, J., Rodriguez, L. G., \& Ramón, D. K. (2015). Understanding Classroom Discourse and Interaction. In N. Markee (Ed.), The Handbook of Classroom Discourse and Interaction (pp. 44-59). New York, NY: John Wiley \& Sons. https://doi.org/10.1002/9781118531242.ch3

Toepell, S. (2010). Lehrertraining im deutschen Sprachraum. Einzeldarstellungen und Entwicklungsverläufe. München: Herbert Utz.

Van der Westhuizen, C. (2015). Video Annotation for Effective Feedback and Reflection on Micro-Lessons in a Collaborative Blended Learning Environment to Promote Self-Directed Learning Skills. International Journal of Learning, Teaching and Educational Research, 11(3), 88-108. Retrieved from https://www.ijlter.org/index.php/ijlter/article/view/343

Watzlawick, P., Beavin, J., \& Jackson, D. D. (1967). Pragmatics of Human Communication. A Study of Interactional Patterns, Pathologies, and Paradoxes. New York, NY: Norton.

White, K. W. (2016). Teacher Communication. A Guide to Relational, Organizational, and Classroom Communication. Lanham: Rowman \& Littlefield.

Zhanabekova, M. (2014). The common climate of classroom communication. Procedia-Social and Behavioral Sciences, 114(2014), 579-583. https://doi.org/10.1016/j.sbspro.2013.12.750

Zifreund, W. (1966). Konzept für ein Training des Lehrerverhaltens mit Fernseh-Aufzeichnungen in Kleingruppen-Seminaren. Berlin: Cornelsen.

\section{Copyrights}

Copyright for this article is retained by the author(s), with first publication rights granted to the journal.

This is an open-access article distributed under the terms and conditions of the Creative Commons Attribution license (http://creativecommons.org/licenses/by/4.0/). 